\title{
P02-219
}

\section{DAYHOSPITAL OF THE PSYCHIATRY DEPARTMENT OF HOSPITAL DE SÃO JOÃO: THE LAST THREE AND A HALF YEARS}

I. Domingues, R. Pedrosa, V. Sousa, J. Marques, A. Martins, R. Curral, A. Palha, A. Roma Torres

Hospital de São João, Porto, Portugal

The Day Hospital of Hospital de São João was one of the pioneers in Portugal, and it began to work in July 1970. In those days, the main purpose was to reduce the number of full hospitalizations, and to aid the reinsertion of patients discharged from the Inpatient Unit. In a previous study, presented in the I Congresso Nacional de Psiquiatria (2005, Portugal), the first 34 years of this Day Hospital (from 1970 to 2004) were analyzed - some changes were noted during that period, namely the type of diagnosis and the hospitalization length. The main purpose of the present study was to characterize the patients that were treated in the Day Hospital of Hospital de São João during the last 3 and half years (Jan 2005- Jul 2008; $n=302$ ), according to age, gender, diagnosis, length of hospitalization, and occupation rate. Then, these data were compared to the data of the previous study (firsts 34 years, in groups of 5 years). For this purpose, the authors used the Qui Square Test and the Kruskal - Wallis Test. It was also analyzed the distribution of the diagnosis according to gender and to length of hospitalization. 